\title{
The biochemical basis of antioxidant therapy in critical illness
}

\author{
Simon Eaton \\ Unit of Paediatric Surgery and Biochemistry, Endocrinology and Metabolism Unit, Institute of Child Health \\ (University College London), 30 Guilford Street, London WC1N 1EH, UK
}

\begin{abstract}
During critical illness free radical production may increase as a result of, for example, sepsis or tissue trauma. In addition, because of a potential for increased losses, and the possibility of inadequate nutrition, the antioxidant defences of the body may become compromised. Thus, the delicate balance between free radicals and antioxidants may be disturbed. Various nutritional and pharmacological strategies to enhance antioxidant defences have been proposed, which aim either to maintain or enhance endogenous antioxidant stores or to provide alternative antioxidant agents. Trace elements and amino acids are particularly important, and their synergistic role in the maintenance of the body's antioxidant defence network will be discussed.
\end{abstract}

Critical illness: Free radical production: Antioxidant therapy: Sepsis

Free radicals and antioxidants are terms that are in common parlance. However, free radicals are usually considered to be deleterious, and it is often forgotten that free radicals and other reactive species perform many essential functions. During critical illness patients are exposed to many factors that may lead to depletion of antioxidant defences and increases in free radical production. Nutritional provision of antioxidants and their precursors enables maintenance of whole-body antioxidant defences without jeopardising the essential benefits of free radical production.

Free radicals, reactive oxygen species and reactive nitrogen species

Free radicals are chemicals that contain unpaired electrons, which make them very reactive and able to damage many cellular and extracellular components. Some examples of free radicals are superoxide, lipid peroxides, hydroxyl radicals and NO. 'Reactive oxygen species' (ROS) and 'reactive nitrogen species' are terms that are frequently used interchangeably with 'free radicals', although this usage may not be strictly correct because they may not contain unpaired electrons. ROS and reactive nitrogen species may be formed from, or give rise to, free radicals and some antioxidants (e.g. glutathione) may be active against more than one class.

\section{Why do all these harmful compounds have to be dealt with?}

From an evolutionary perspective, these compounds have to be dealt with as a consequence of living in aerobic environments. The $\mathrm{O}_{2}$ content of the atmosphere started increasing $2500 \times 10^{6}$ years ago and is now $21 \%$; at times it has been as high as $35 \%$. In order to survive in hostile environments in which reactive chemicals are constantly being formed, organisms have harnessed $\mathrm{O}_{2}$ for energy metabolism and other functions, and have developed elaborate and synergistic antioxidant defences to cope with these chemicals. Free radicals, ROS and reactive nitrogen species are always present and antioxidant defences are always active. $\mathrm{O}_{2}$ is used in the mitochondrial respiratory chain, which is so important in ATP generation and is particularly vulnerable during critical illness. As a consequence of using $\mathrm{O}_{2}$, the mitochondrial respiratory chain is one of the major sites of free radical production in the body. In order to even deliver $\mathrm{O}_{2}$ to cells, $\mathrm{O}_{2}$ has to be transported bound to $\mathrm{Hb}$ in a way that also leads to the production of substantial quantities of ROS. Maintenance of vascular tone requires the reactive nitrogen species NO, and the reaction of this $\mathrm{NO}$ with ROS formed by $\mathrm{Hb}$ and $\mathrm{O}_{2}$ transport may generate yet more reactive species such as peroxynitrite, even in healthy individuals. Yet, in critical illness there is another, extremely important, function that is triggered and massively increases whole-body

Abbreviations: ROS, reactive oxygen species; SOD, superoxide dismutase.

Corresponding author: Simon Eaton, fax +44 207404 6181, email s.eaton@ich.ucl.ac.uk 


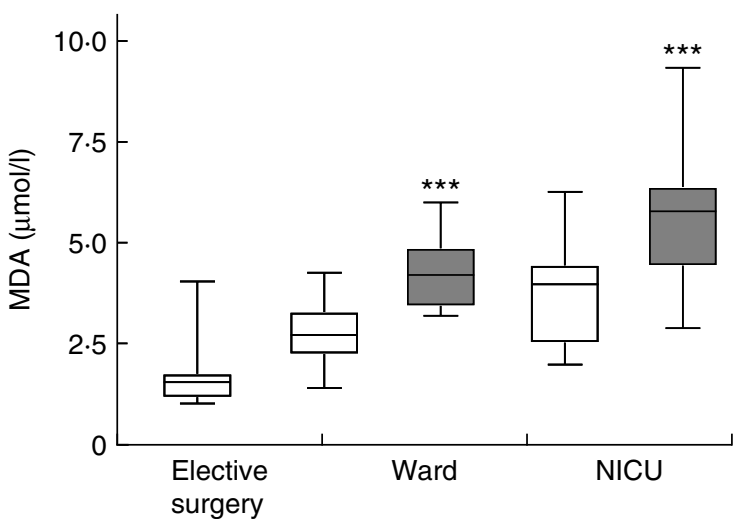

Fig. 1. A comparison of plasma malondialdehyde (MDA; lipid peroxidation marker) concentrations for infants undergoing elective surgery, stable after having undergone a major operation (ward) or in the neonatal intensive care unit (NICU). Patients are further divided into those receiving enteral nutrition $(\square)$ and those receiving total parenteral nutrition $(\square)$. Values are medians represented by the horizontal bar within the box and interquartile ranges represented by upper and lower limits of the box and ranges represented by vertical bars. Mean values were significantly different from those for patients receiving enteral nutrition: ${ }^{\star \star \star} P<0 \cdot 001$. Mean values for the elective surgery, ward and NICU patient groups were significantly different $(P<0 \cdot 001)$. (Redrawn from Basu et al. 1999.)

production of reactive species, i.e. bacterial killing. Activated leucocytes produce a vast array of reactive compounds that are indispensable for the phagocytosis and killing of pathogens, and these reactive compounds can very easily damage host tissues if their reactivity is not checked by antioxidants.

\section{Free radical production during critical illness}

During critical illness many factors can combine to dramatically increase free radical production and tissue damage. First, during a systemic inflammatory response to a particular cause (infection, bowel perforation, trauma, surgery etc.) bacterial killing will be increased as previously described. In addition, during various forms of critical illness other factors may yet further increase production of these reactive species: elevation of $\mathrm{O}_{2}$ concentration for respiratory compromise; NO therapy; ischaemia/reperfusion injury and its consequences; parenteral nutrition; impaired kidney function leading to decreased clearance of substances that may be pro-oxidant; fluid and electrolyte imbalances etc. In addition, massive losses of antioxidants may occur as a result of capillary leak, impaired renal reabsorption and other factors. For example, the plasma concentration of a marker of lipid peroxidation and free radical production (malondialdehyde) has been measured in infants before minor surgery, stable infants on the ward recovering from a major operation and critically-ill infants in the neonatal intensive care unit (Basu et al. 1999). Some of these infants were receiving enteral nutrition and some were receiving parenteral nutrition. As can be seen in Fig. 1, lipid peroxidation increases in the order elective surgery $<$ major surgery $<$ neonatal intensive care unit, but also increases in each patient group if infants are fed parenterally as compared with enterally.

\section{Antioxidant defences}

The antioxidant defences of the body consist of several interacting systems. They can be divided into: antioxidant enzymes; fat-soluble antioxidants; water-soluble antioxidants; non-specific antioxidants. Together, under most circumstances, these various systems protect membranes, intracellular contents, organelles and extracellular fluids from excessive damage by reactive species. Several of these systems can become depleted during excessive free radical production (e.g. during critical illness) and some may be amenable to manipulation, either pharmacologically or nutritionally. The present review will consider each system in turn and whether there is potential for nutritional or pharmacological intervention during critical illness, concentrating on those systems for which interventions have been tried in human critical illness, but also discussing some use in animal models.

\section{Antioxidant enzymes}

The major ROS and free radical produced in the bacterial killing process is superoxide, generated by the action of NADPH oxidase. Superoxide is also produced in substantial quantities by the mitochondrial respiratory chain, xanthine oxidase and the metabolism of drugs and endogenous compounds. Superoxide is specifically acted on by the enzyme superoxide dismutase (SOD) in the mitochondria (Mn-SOD), cytosol (Cu,Zn-SOD) and extracellular fluids ( $\mathrm{Cu}, \mathrm{Zn}-\mathrm{SOD})$. SOD is difficult to use therapeutically, although several variants of different liposomal formulations have been used in animal studies. The problem is, as with other enzymes, one of delivery in an active state. A gel consisting of liposomally-encapsulated human recombinant $\mathrm{Cu}, \mathrm{Zn}$-SOD has been used for the treatment of a urological disease (Peyronie's disease; Riedl et al. 2005), and tracheal installation has been used, with some success, in premature infants at risk from lung sequelae (Davis et al. 1997). In the latter paper the authors tempered their positive findings with the following quotes, both of which are pertinent to all studies in which the aim is to modify antioxidant defences: '.. supports a critical role of SOD in the prevention of ROS-induced lung injury, caution should be exercised with the use of antioxidants such as SOD, especially in high-risk premature infants. ROS may potentially be toxic, but may also have important cellular functions in many organ systems ...' and 'Although administration of human recombinant $\mathrm{Cu}, \mathrm{Zn}$ SOD could potentially interfere with superoxide generation and bacterial killing by neutrophils and macrophages, the incidence of late-onset sepsis and pneumonia were comparable between groups .... Much interest has been expressed in the potential of chemical compounds that act like SOD ('SOD mimetics') to have beneficial effects in critical illness (Cuzzocrea et al. 2001; Salvemini \& Cuzzocrea, 2003; Tuder et al. 2003), as well as in the prevention of ageing (Melov et al. 2000). However, the same problems may exist to restrict their clinical usage, i.e. 
interference with essential free radical-dependent processes such as bacterial killing. One of these compounds, M-40403, is currently in a phase-2 trial for the prevention of pain (Di Napoli \& Papa, 2005). The reaction of SOD with superoxide generates $\mathrm{H}_{2} \mathrm{O}_{2}$, which is itself a ROS that can damage cellular components and give rise to other reactive compounds. This $\mathrm{H}_{2} \mathrm{O}_{2}$ is detoxified by two enzyme systems, catalase and glutathione peroxidase. Catalase decomposes $\mathrm{H}_{2} \mathrm{O}_{2}$ to water and $\mathrm{O}_{2}$ and contains $\mathrm{Fe}$ at its catalytic centre, whereas glutathione peroxidase detoxifies $\mathrm{H}_{2} \mathrm{O}_{2}$ by reacting it with the co-substrate glutathione in the reduced form to yield oxidised glutathione (i.e. two glutathione molecules connected by a disulphide bond) plus water. This oxidised glutathione is then regenerated by the enzyme glutathione reductase, using NADPH from the pentose phosphate pathway. Although it would appear that catalase and glutathione peroxidase have identical functions, they have differing locations and reactivities; catalase is mainly localised in peroxisomes, and it therefore acts mainly on $\mathrm{H}_{2} \mathrm{O}_{2}$ generated either in the cytosol or in the peroxisome itself. Apart from heart mitochondria, which do appear to possess a catalase activity, mitochondria lack catalase and so rely on glutathione peroxidase to decompose $\mathrm{H}_{2} \mathrm{O}_{2}$ generated by MnSOD. In addition, glutathione peroxidase is found in the cytosol. However, glutathione peroxidase has two other characteristics that differ from catalase: it is active towards lipid hydroperoxides and so protects cell membranes; it is active against low concentrations of $\mathrm{H}_{2} \mathrm{O}_{2}$, whereas catalase has a high $K_{m}$ and so has a high rate of $\mathrm{H}_{2} \mathrm{O}_{2}$ destruction at high concentrations. Administration of catalase is not a therapeutic option because the Fe present in catalase preparations would be likely to behave as a prooxidant. However, nutritional intervention to maintain glutathione peroxidase activity is a potentially-important therapeutic option in critical illness. These aspects will be considered later in the present article.

Just as there are chemical compounds that mimic SOD activity, there are compounds that mimic glutathione peroxidase. Ebselen is a Se-containing glutathione peroxidase mimetic that has been used clinically in the area of neuro-intensive care (Saito et al. 1998; Yamaguchi et al. 1998; Ogawa et al. 1999). Recently, a mitochondriallytargetted glutathione peroxidase mimetic, 2-[4-(4-triphenylphosphoniobutoxy) phenyl]-1,2-benzisoselenazol)3(2H)-one iodide ('MitoPeroxidase'), has been synthesised (Filipovska et al. 2005).

\section{Fat-soluble antioxidants}

Many ROS are produced in proximity to membranes, and as polyunsaturated lipids in membranes are particularly vulnerable to peroxidative damage that can propagate from lipid to lipid, it is important that membranes are protected from the effects of these compounds. Vitamin E, of which the major biological isomer is $\alpha$-tocopherol, is particularly important in protecting membranes because it can interrupt this process, i.e. it is a chain-breaking antioxidant. In this process the relatively stable $\alpha$-tocopheryl radical can be formed, which can be recycled by vitamin $\mathrm{C}$ or by ubiquinone (Beyer, 1994). Studies that have aimed to determine whether vitamin $\mathrm{E}$ status is compromised during critical illness have yielded equivocal results; a number of studies have shown that vitamin $\mathrm{E}$ is depleted, whereas others have not supported this finding. These results may, however, depend on how the plasma vitamin E concentration is expressed, i.e. as absolute plasma vitamin $\mathrm{E}$ concentration, or as plasma vitamin E concentration:plasma cholesterol, which is thought to be more physiologically relevant because most of the vitamin $\mathrm{E}$ is carried in plasma lipoproteins and its absolute concentration will vary simply as a function of lipoprotein concentration independently of alterations in vitamin E supply and demand. For example, a study by (Quasim et al. 2003) has found that vitamin $\mathrm{E}$ concentration is decreased in critical illness, whereas when corrected for plasma cholesterol there is in fact an increase in vitamin $\mathrm{E}$ concentration. $\alpha$-Tocopherol can be oxidised to $\alpha$-tocopheronic acid, which then yields $\alpha$-tocopheronolactone (Simon et al. 1956), which can be detected in urine and has been suggested to be a marker of oxidative stress (Pope et al. 2002). This compound is increased in infants with sepsis compared with controls, suggesting that vitamin E consumption is increased during critical illness $(\mathrm{G}$ Panagou, K Mills, M Chowdhury, A Pierro, S Eaton and DPR Muller, unpublished results). In addition, tocopherols, especially $\gamma$-tocopherol, can be nitrated in vivo by reactive nitrogen species, which are known to be elevated in critical illness (Christen et al. 1997; Morton et al. 2002). Whether either of these two routes quantitatively depletes the vitamin $\mathrm{E}$ pool is unknown. There have been few trials of vitamin $\mathrm{E}$ in critical illness, partly because the poor solubility of vitamin $\mathrm{E}$ in aqueous solutions makes it difficult to administer intravenously, and in those trials in which vitamin $\mathrm{E}$ has been used in critical illness it has frequently also been administered in combination with vitamin C (Nathens et al. 2002; Crimi et al. 2004).

Ubiquinone, which has a crucial role in the mitochondrial electron transport chain, is also found in other membranes where, in the reduced form, it can act as an antioxidant in concert with vitamin E (Beyer, 1994). There does not, however, appear to be a particular rationale for ubiquinone supplementation during critical illness.

Carotenoids (e.g. lycopene, $\beta$-carotene) are important antioxidants in plants and may have some antioxidant function in man, although it is likely that $\beta$-carotene is more important as a vitamin A precursor. There are drastic decreases in circulating carotenoids during critical illness (Quasim et al. 2003), but there are no studies that have examined a therapeutic role in critical illness.

\section{Water-soluble antioxidants}

Vitamin C (ascorbic acid) is one of the most important extracellular antioxidants, working in conjunction with vitamin $\mathrm{E}$ as described earlier. It is also an essential cofactor for several enzymes. It cannot be synthesised within the body, so the diet must contain adequate vitamin $\mathrm{C}$ to maintain whole-body levels. Vitamin $\mathrm{C}$ appears to be dramatically decreased in critical illness, and there are lower levels in patients with multiple organ failure than in critically-ill patients without multiple organ failure (Borrelli et al. 1996; Fig. 2). Vitamin C has been used in 


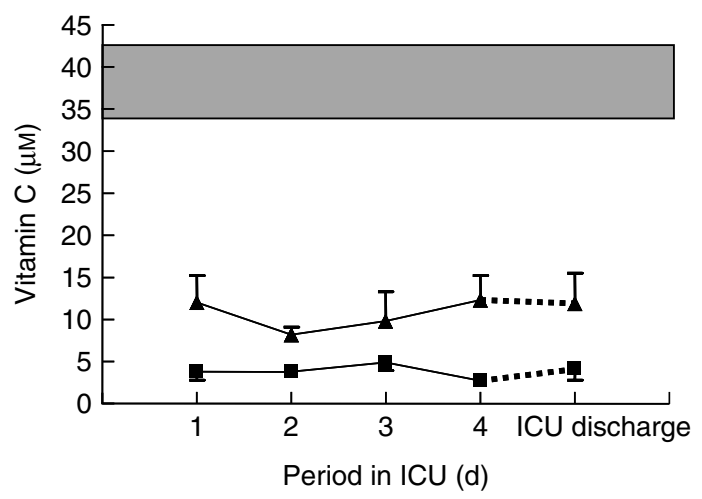

Fig. 2. Vitamin $C$ (ascorbate) concentration in the plasma of critically-ill patients with $(\boldsymbol{\square})$ and without $(\mathbf{\Lambda})$ multiple-organ failure, and a normal healthy adult range for plasma vitamin $C(\square)$. ICU, intensive care unit. Values are means with their standard errors represented by vertical bars. (Data redrawn from Borrelli et al. 1996 and Johnston \& Cox, 2001.)

several studies in patients in intensive care units, both alone and in conjunction with vitamin $\mathrm{E}$.

The other main water-soluble antioxidant is glutathione. This tripeptide, $\gamma$-glutamate-cysteinyl-glycine, is a cosubstrate of the enzyme glutathione peroxidase, which is essential for detoxification of $\mathrm{H}_{2} \mathrm{O}_{2}$ and lipid peroxides as described earlier. Additionally, glutathione may become depleted during oxidative stress by reaction with $\mathrm{HClO}$ produced as part of the bacterial killing process (Pullar et al. 2001), and can react with high levels of NO to form $S$-nitroso-glutathione. Lipid peroxidation occurs extensively during sepsis, and lipid peroxidation products such as 4-hydroxynonenal can be conjugated and excreted, leading to loss of hepatic glutathione (Wang \& Ballatori, 1998; Laurent et al. 1999). Glutathione is thought to be particularly important in the protection of mitochondrial respiratory chain complexes (Bolanos et al. 1996; Clementi et al. 1998), and it has recently been shown for adult patients with sepsis that complex I activity is positively correlated with mitochondrial glutathione content and is lower in non-survivors than in survivors (Brealey et al. 2002). The liver is crucial to maintaining whole-body glutathione levels, and during critical illness or sepsis hepatic glutathione efflux is increased, which can result in lower hepatic glutathione levels (Lauterburg et al. 1984; Sugino et al. 1989; Jaeschke, 1992; Ookhtens et al. 1994; Minamiyama et al. 1996). The demand for cysteine is increased during sepsis (Malmezat et al. 1998), partly to maintain glutathione levels and also because many acutephase proteins have a high cysteine content. Flux through the trans-sulphuration pathway is increased (Malmezat et al. 2000 b), but the increase in cysteine synthesis is not sufficient to account for the increased cysteine flux, and muscle protein catabolism is necessary to provide cysteine. In rats with sepsis protein breakdown and increased transsulfuration together provide enough cysteine for increased glutathione synthesis (Malmezat et al. 2000a). However, in infants and children with sepsis increased protein breakdown and increased plasma cysteine flux are not sufficient to maintain whole-blood glutathione synthesis, which is decreased by $60 \%$ (Lyons et al. 2001). This decrease could be a result of inadequate supply of intracellular glutamate, glycine or ATP. Extrahepatic glutathione stores can also be depleted because of inadequate supply of precursors, e.g. in muscle post-surgically (Luo et al. 1996) or during sepsis (Brealey et al. 2002).

\section{Nutritional and therapeutic modulation of the glutathione system in critical illness}

Although intravenous glutathione has been shown to have beneficial effects on lipid peroxidation in a study of patients with sepsis (Ortolani et al. 2000), oral or intravenous delivery of glutathione is not thought to be very effective, because glutathione is not directly taken up into cells but is hydrolysed extracellularly before it is taken up. More interest has been shown in the administration of glutathione esters such as glutathione-monoethyl ester, which can be taken up directly by cells, although there are potential problems with contamination and/or plasma esterases. There have been no studies of the use of glutathione esters in human subjects and there are no pharmaceutical preparations. However, administration of glutathione could be effective by providing the amino acids required for glutathione synthesis, and many studies have been performed with the aim of boosting glutathione levels by providing the constituent amino acids or their precursors.

For glutathione synthesis extracellular glutamine is a better source of intracellular glutamate than extracellular glutamate, so that depletion of hepatocyte glutathione during oxidation can be counteracted by glutamine but not by glutamate (Markley et al. 2002). During sepsis glutamine is mobilised from muscle and lung, and net glutamine utilisation exceeds production such that glutamine may become a 'conditionally essential' nutrient (Lacey \& Wilmore, 1990) that is limiting for glutathione synthesis. However, the actual flux of glutamine into glutathione and whether this flux is altered during sepsis is unknown. Under conditions in which the lack of intracellular glutamate may limit glutathione synthesis glutamine can help maintain glutathione levels, e.g. paracetamol overdose (Hong et al. 1992), parenteral nutrition (Denno et al. 1996) or after surgery (Flaring et al. 2003), although oral glutamine fails to increase glutathione levels in healthy individuals (Valencia et al. 2002). There is some evidence to support the beneficial effects of glutamine during critical illness, as suggested by a recent meta-analysis (Avenell, 2006), although whether these effects are mediated via the glutathione system is not known.

Cysteine supply is often compromised during sepsis, and several drugs have been proposed to increase cysteine availability for glutathione synthesis. The 5-oxoproline analogue L-2-oxothiozalidine-4-carboxylate generates intracellular cysteine and can increase glutathione levels (Bernard et al. 1997; Moberly et al. 1998) and prevent sepsis-related cardiac dysfunction (Moberly et al. 1998; Poon et al. 1998). Similarly, $N$-acetyl-cysteine, which can be taken up by cells and hydrolysed to cysteine, can increase blood and lung glutathione levels in patients with acute respiratory distress syndrome (Bernard et al. 1997) or pulmonary fibrosis (Meyer et al. 1995), and although 


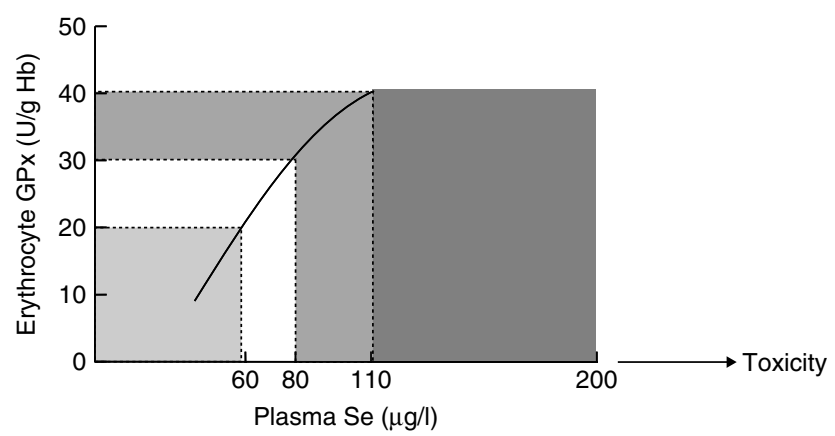

Fig. 3. Erythrocyte glutathione peroxidase (GPx) activity as a function of plasma selenium levels. $(\square)$, 'Deficient'; $(\square)$, 'submaximal'; ( $\square$ ), 'maximal'.

lung glutathione levels are unaffected in controls (Meyer et al. 1995), blood glutathione levels are increased (Roes et al. 2002). Lipoic acid has also been suggested to maintain glutathione levels by allowing cystine reduction to cysteine and thereby increasing intracellular cysteine levels (Han et al. 1997). Additionally, lipoic acid may also help to recycle oxidised glutathione to reduced glutathione (Porras et al. 2002).

Little attention has been paid to the role of glycine supply in the maintenance of glutathione levels. However, glycine is known to have beneficial effects in sepsis (Yang et al. 2001), and a recent in vitro study has shown that glycine enhances glutathione levels when glutamine is low but decreases glutathione levels when glutamine is higher (Wessner et al. 2003).

In addition to the maintenance of tissue glutathione levels, in order to ensure optimal functioning of the glutathione system glutathione peroxidase activity should be adequate. The trace element $\mathrm{Se}$ is incorporated into the amino acid selenocysteine, which forms the active site of the different glutathione peroxidase isoforms. Se intake has fallen in the UK, so that current daily intake is markedly less than recommendations (Rayman, 2000; Jackson et al. 2003). This lowered intake results in submaximal glutathione peroxidase activity (Fig. 3), which may have adverse effects in the general population, e.g. increased cancer risk (Rayman, 2000) and increased risk of cardiovascular events (Blankenberg et al. 2003). Critically-ill patients are likely to have additional Se losses such as through exudates, renal therapy etc., so that many patients may have low Se levels (Angstwurm et al. 1999; Berger et al. 2001; Hardy, 2005). Supplementation of critically-ill patients with Se has been carried out in several trials, and some of these trials have shown either a benefit (Angstwurm et al. 1999) or a trend towards benefit. Thus, in meta-analyses Se supplementation (in some trials $\mathrm{Se}$ is used with other antioxidants) shows a trend towards lower mortality (relative risk 0.59 (95\% CI $0.32,1.08), P<0.09$; Heyland et al. 2005), although it has been pointed out that several of the included trials were small and of poor quality methodologically, so that the authors of another meta-analysis have recommended a large randomised controlled trial (Avenell et al. 2004). Two large multicentre randomised controlled trials of $\mathrm{Se}$ and glutamine supplementation in critical illness are now underway, the
REDOX study (Critical Care Nutrition, 2006) and the SIGNET trial (Health Services Research Unit, University of Aberdeen, 2006).

Other water-soluble compounds with antioxidant activity

There is a host of other chemicals and proteins with antioxidant activity; however, whether these compounds have any biologically-important antioxidant activity is uncertain. An example of these compounds is the $\alpha$-amino acid taurine, which is found in high concentration in the heart and in neutrophils. An antioxidant function for taurine in the heart is unproven, but in neutrophils taurine reacts with bactericidal $\mathrm{HClO}$ to form taurine-chloramine, which may have further immunomodulatory effects (Schuller-Levis \& Park, 2004). Plasma components with antioxidant activity include uric acid (Waring et al. 2001), bilirubin (Stocker et al. 1987) and albumin (Halliwell, 1988). In a test in which plasma is exposed to an exogenous oxidant challenge, uric acid accounts for $33 \%$ of the plasma total antioxidant capacity, with bilirubin, albumin, vitamin $\mathrm{C}$ and vitamin $\mathrm{E}$ accounting for 2, 43, 9 and $3 \%$ of the plasma total antioxidant capacity respectively (Miller et al. 1993). Although this type of oxidant challenge is clearly artificial, albumin appears to be an important antioxidant. The reason for this activity is that albumin has a free thiol group that is readily oxidised by reactive species, and the high concentration of albumin in plasma means that this thiol group contributes markedly to plasma free thiols and hence to plasma antioxidant capacity (Quinlan et al. 1998, 2004). Some plasma albumin is naturally found in oxidised forms and the proportion in the reduced form (i.e. effective as an antioxidant) can vary (Era et al. 1995); for example, in healthy young adults $76 \%$ is present in the reduced form, whereas in healthy elderly subjects this percentage is decreased to 46 (Era et al. 1995). The redox state is also altered by cardiac surgery, diabetes, renal dysfunction and haemodialysis (Suzuki et al. 1992; Hayakawa et al. 1997; Soejima et al. 2004; Terawaki et al. 2004); thus, although it is not known whether there is a change in redox state in critically-ill populations, it is likely to be altered compared with that of healthy young males. Albumin is given to many critically-ill patients as an oncotic support and, although this treatment repletes plasma thiols (Quinlan et al. 1998, 2004), most commercial sources of albumin have a decreased proportion of the thiol groups in the reduced form compared with that in the plasma of healthy adult males (Bar-Or et al. 2005).

\section{Conclusions}

Although there is much data to show that free radical activity is increased in critical illness, and that the levels of many plasma antioxidants are decreased, studies of antioxidant supplementation in critical illness have mostly been carried out on a small scale.

\section{References}

Angstwurm MWA, Schottdorf J, Schopohl J \& Gaertner R (1999) Selenium replacement in patients with severe systemic 
inflammatory response syndrome improves clinical outcome. Critical Care Medicine 27, 1807-1813.

Avenell A (2006) Glutamine in critical care: current evidence from systematic reviews. Proceedings of the Nutrition Society 65, 000-000.

Avenell A, Noble DW, Barr J \& Engelhardt T (2004) Selenium Supplementation for Critically Ill Adults. The Cochrane Database of Systematic Reviews. Bognor Regis, West Sussex: John Wiley \& Sons Ltd.

Bar-Or D, Bar-Or R, Rael LT, Gardner DK, Slone DS \& Craun ML (2005) Heterogeneity and oxidation status of commercial human albumin preparations in clinical use. Critical Care Medicine 33, 1638-1641.

Basu R, Muller DPR, Papp E, Merryweather I, Eaton S, Klein N \& Pierro A (1999) Free radical formation in infants: the effect of critical illness, parenteral nutrition, and enteral feeding. Journal of Pediatric Surgery 34, 1091-1095.

Berger MM, Baines M, Chiolero RL, Wardle CA, Cayeux C \& Shenkin A (2001) Influence of early trace element and vitamin E supplements on antioxidant status after major trauma: a controlled trial. Nutrition Research 21, 41-54.

Bernard GR, Wheeler AP, Arons MM, Morris PE, Paz HL, Russell JA et al. (1997) A trial of antioxidants N-acetylcysteine and procysteine in ARDS. Chest 112, 164-172.

Beyer RE (1994) The role of ascorbate in antioxidant protection of biomembranes - interaction with vitamin-E and coenzyme-Q. Journal of Bioenergetics and Biomembranes 26, 349-358.

Blankenberg S, Rupprecht HJ, Bickel C, Torzewski M, Hafner G, Tiret L, Smieja M, Cambien F, Meyer J \& Lackner KJ (2003) Glutathione peroxidase 1 activity and cardiovascular events in patients with coronary artery disease. New England Journal of Medicine 349, 1605-1613.

Bolanos JP, Heales SJR, Peuchen S, Barker JE, Land JM \& Clark JB (1996) Nitric oxide-mediated mitochondrial damage: A potential neuroprotective role for glutathione. Free Radical Biology and Medicine 21, 995-1001.

Borrelli E, Roux-Lombard P, Grau GE, Girardin E, Ricou B, Dayer JM \& Suter PM (1996) Plasma concentrations of cytokines, their soluble receptors, and antioxidant vitamins can predict the development of multiple organ failure in patients at risk. Critical Care Medicine 24, 392-397.

Brealey D, Brand M, Hargreaves I, Heales S, Land J, Smolenski R, Davies NA, Cooper CE \& Singer M (2002) Association between mitochondrial dysfunction and severity and outcome of septic shock. Lancet 360, 219-223.

Christen S, Woodall AA, Shigenaga MK, Southwell-Keely PT, Duncan MW \& Ames BN (1997) Gamma-tocopherol traps mutagenic electrophiles such as $\mathrm{NO}_{(\mathrm{X})}$ and complements alphatocopherol: Physiological implications. Proceedings of the National Academy of Sciences USA 94, 3217-3222.

Clementi E, Brown GC, Feelisch M \& Moncada S (1998) Persistent inhibition of cell respiration by nitric oxide: Crucial role of $S$-nitrosylation of mitochondrial complex I and protective action of glutathione. Proceedings of the National Academy of Sciences USA 95, 7631-7636.

Crimi E, Liguori A, Condorelli M, Cioffi M, Astuto M, Bontempo P et al. (2004) The beneficial effects of antioxidant supplementation in enteral feeding in critically ill patients: A prospective, randomized, double-blind, placebo-controlled trial. Anesthesia and Analgesia 99, 857-863.

Critical Care Nutrition (2006) REducing Deaths due to Oxidative Stress Study. http://www.criticalcarenutrition.com/redoxs/ redoxHome.htm

Cuzzocrea S, Mazzon E, Dugo L, Caputi AP, Aston K, Riley DP \& Salvemini D (2001) Protective effects of a new stable, highly active SOD mimetic, M40401 in splanchnic artery occlusion and reperfusion. British Journal of Pharmacology 132, 19-29.

Davis JM, Rosenfeld WN, Richter SE, Parad MR, Gewolb IH, Spitzer AR et al. (1997) Safety and pharmacokinetics of multiple doses of recombinant human $\mathrm{CuZn}$ superoxide dismutase administered intratracheally to premature neonates with respiratory distress syndrome. Pediatrics 100, 24-30.

Denno R, Rounds JD, Faris R, Holejko LB \& Wilmore DW (1996) Glutamine-enriched total parenteral nutrition enhances plasma glutathione in the resting state. Journal of Surgical Research 61, 35-38.

Di Napoli M \& Papa F (2005) M-40403 Metaphore pharmaceuticals. IDrugs 8, 67-76.

Era S, Kuwata K, Imai H, Nakamura K, Hayashi T \& Sogami M (1995) Age-related change in redox state of human serumalbumin. Biochimica et Biophysica Acta 1247, 12-16.

Filipovska A, Kelso GF, Brown SE, Beer SM, Smith RAJ \& Murphy MP (2005) Synthesis and characterization of a triphenylphosphonium-conjugated peroxidase mimetic Insights into the interaction of ebselen with mitochondria. Journal of Biological Chemistry 280, 24113-24126.

Flaring UB, Rooyackers OE, Wernerman J \& Hammarqvist F (2003) Glutamine attenuates post-traumatic glutathione depletion in human muscle. Clinical Science (London) 104, 275-282.

Halliwell B (1988) Albumin - an important extracellular antioxidant? Biochemical Pharmacology 37, 569-571.

Han D, Handelman G, Marcocci L, Sen CK, Roy S, Kobuchi H, Tritschler HJ, Flohe L \& Packer L (1997) Lipoic acid increases de novo synthesis of cellular glutathione by improving cystine utilization. Biofactors 6, 321-338.

Hardy G (2005) Selenium: an important component of sepsis therapy. British Journal of Intensive Care 15, 28-36.

Hayakawa A, Kuwata K, Era S, Sogami M, Shimonaka H, Yamamoto M, Dohi S \& Hirose H (1997) Alteration of redox state of human serum albumin in patients under anesthesia and invasive surgery. Journal of Chromatography 698B, 27-33.

Health Services Research Unit, University of Aberdeen (2006) Scottish multicentre trial of glutamine and selenium supplemented parenteral nutrition for critically ill patients (SIGNET trial). http://www.abdn.ac.uk/hsru/hta/signet.shtml

Heyland DK, Dhaliwal R, Suchner U \& Berger MM (2005) Antioxidant nutrients: a systematic review of trace elements and vitamins in the critically ill patient. Intensive Care Medicine 31, 327-337.

Hong RW, Rounds JD, Helton WS, Robinson MK \& Wilmore DW (1992) Glutamine preserves liver glutathione after lethal hepatic - injury. Annals of Surgery 215, 114-119.

Jackson MJ, Broome CS \& McArdle F (2003) Marginal dietary selenium intakes in the UK: Are there functional consequences? Journal of Nutrition 133, 1557S-1559S.

Jaeschke H (1992) Enhanced sinusoidal glutathione efflux during endotoxin-induced oxidant stress in vivo. American Journal of Physiology 263, G60-G68.

Johnston CS \& Cox SK (2001) Plasma-saturating intakes of vitamin $\mathrm{C}$ confer maximal antioxidant protection to plasma. Journal of the American College of Nutrition 20, 623-627.

Lacey JM \& Wilmore DW (1990) Is glutamine a conditionally essential amino acid? Nutrition Reviews 48, 297-309.

Laurent A, Alary J, Debrauwer L \& Cravedi JP (1999) Analysis in the rat of 4-hydroxynonenal metabolites excreted in bile: Evidence of enterohepatic circulation of these byproducts of lipid peroxidation. Chemical Research in Toxicology 12 , 887-894.

Lauterburg BH, Adams JD \& Mitchell JR (1984) Hepatic glutathione homeostasis in the rat-efflux accounts for glutathione turnover. Hepatology 4, 586-590. 
Luo JL, Hammarqvist F, Andersson K \& Wernerman J (1996) Skeletal muscle glutathione after surgical trauma. Annals of Surgery 223, 420-427.

Lyons J, Rauh-Pfeiffer A, Ming-Yu Y, Lu XM, Zurakowski D, Curley M et al. (2001) Cysteine metabolism and whole blood glutathione synthesis in septic pediatric patients. Critical Care Medicine 29, 870-877.

Malmezat T, Breuille D, Capitan P, Mirand PP \& Obled C (2000a) Glutathione turnover is increased during the acute phase of sepsis in rats. Journal of Nutrition 130, 1239-1246.

Malmezat T, Breuille D, Pouyet C, Buffiere C, Denis P, Mirand PP \& Obled C (2000b) Methionine transsulfuration is increased during sepsis in rats. American Journal of Physiology 279, E1391-E1397.

Malmezat T, Breuille D, Pouyet C, Mirand PP \& Obled C (1998) Metabolism of cysteine is modified during the acute phase of sepsis in rats. Journal of Nutrition 128, 97-105.

Markley MA, Pierro A \& Eaton S (2002) Hepatocyte mitochondrial metabolism is inhibited in neonatal rat endotoxaemia: effects of glutamine. Clinical Science (London) 102, 337-344.

Melov S, Ravenscroft J, Malik S, Gill MS, Walker DW, Clayton PE, Wallace DC, Malfroy B, Doctrow SR \& Lithgow GJ (2000) Extension of life span with superoxide dismutase/ catalase mimetics. Science 289, 1567.

Meyer A, Buhl R, Kampf S \& Magnussen H (1995) Intravenous $\mathrm{N}$-acetylcysteine and lung glutathione of patients with pulmonary fibrosis and normals. American Journal of Respiratory and Critical Care Medicine 152, 1055-1060.

Miller NJ, Rice-Evans C, Davies MJ, Gopinathan V \& Milner A (1993) A novel method for measuring antioxidant capacity and its application to monitoring the antioxidant status in premature neonates. Clinical Science (London) 84, 407-412.

Minamiyama Y, Takemura S, Koyama K, Yu H, Miyamoto M \& Inoue M (1996) Dynamic aspects of glutathione and nitric oxide metabolism in endotoxemic rats. American Journal of Physiology 271, G575-G581.

Moberly JB, Logan J, Borum PR, Story KO, Webb LE, Jassal SV et al. (1998) Elevation of whole-blood glutathione in peritoneal dialysis patients by L-2-oxothiazolidine-4-carboxylate, a cysteine prodrug (Procysteine ${ }^{\circledR}$ ). Journal of the American Society of Nephrology 9, 1093-1099.

Morton LW, Ward NC, Croft KD \& Puddey IB (2002) Evidence for the nitration of gamma-tocopherol in vivo: 5-nitro-gammatocopherol is elevated in the plasma of subjects with coronary heart disease. Biochemical Journal 364, 625-628.

Nathens AB, Neff MJ, Jurkovich GJ, Klotz P, Farver K, Ruzinski JT, Radella F, Garcia I \& Maier RV (2002) Randomized, prospective trial of antioxidant supplementation in critically ill surgical patients. Annals of Surgery 236, 814-822.

Ogawa A, Yoshimoto T, Kikuchi H, Sano K, Saito I, Yamaguchi T \& Yasuhara H (1999) Ebselen in acute middle cerebral artery occlusion: A placebo-controlled, double-blind clinical trial. Cerebrovascular Diseases 9, 112-118.

Ookhtens M, Mittur AV \& Erhart NA (1994) Changes in plasma glutathione concentrations, turnover, and disposal in developing rats. American Journal of Physiology 266, R979-R988.

Ortolani O, Conti A, De Gaudio AR, Moraldi E, Cantini Q \& Novelli G (2000) The effect of glutathione and $\mathrm{N}$-acetylcysteine on lipoperoxidative damage in patients with early septic shock. American Journal of Respiratory and Critical Care Medicine 161, 1907-1911.

Poon BY, Goddard CM, Leaf CD, Russell JA \& Walley KR (1998) L-2-oxothiazolidine-4-carboxylic acid prevents endotoxin-induced cardiac dysfunction. American Journal of Respiratory and Critical Care Medicine 158, 1109-1113.

Pope SAS, Green H, Clayton PT, Goss-Sampson MA \& Muller DPR (2002) The possible use of urinary alpha- tocopheronolactone as a biomarker of oxidative stress. Free Radical Research 36, 82-83.

Porras P, Pedrajas JR, Martinez-Galisteo E, Padilla CA, Johansson C, Holmgren A \& Barcena JA (2002) Glutaredoxins catalyze the reduction of glutathione by dihydrolipoamide with high efficiency. Biochemical and Biophysical Research Communications 295, 1046-1051.

Pullar JM, Vissers MCM \& Winterbourn CC (2001) Glutathione oxidation by hypochlorous acid in endothelial cells produces glutathione sulfonamide as a major product but not glutathione disulfide. Journal of Biological Chemistry 276, 22120-22125.

Quasim T, McMillan DC, Talwar D, Sattar N, O'Reilly DSJ \& Kinsella J (2003) Lower concentrations of carotenoids in the critically-ill patient are related to a systemic inflammatory response and increased lipid peroxidation. Clinical Nutrition 22, 459-462.

Quinlan GJ, Margarson MP, Mumby S, Evans TW \& Gutteridge JMC (1998) Administration of albumin to patients with sepsis syndrome: a possible beneficial role in plasma thiol repletion. Clinical Science (London) 95, 459-465.

Quinlan GJ, Mumby S, Martin GS, Bernard GR, Gutteridge JMC \& Evans TW (2004) Albumin influences total plasma antioxidant capacity favorably in patients with acute lung injury. Critical Care Medicine 32, 755-759.

Rayman MP (2000) The importance of selenium to human health. Lancet 356, 233-241.

Riedl CR, Sternig P, Galle G, Langmann F, Vcelar B, Vorauer K, Wagner A, Katinger H \& Pfluger H (2005) Liposomal recombinant human superoxide dismutase for the treatment of Peyronie's disease: A randomized placebo-controlled doubleblind prospective clinical study. European Urology 48, 656-661.

Roes EM, Raijmakers MTM, Peters WHM \& Steegers EAP (2002) Effects of oral $\mathrm{N}$-acetylcysteine on plasma homocysteine and whole blood glutathione levels in healthy, nonpregnant women. Clinical Chemistry and Laboratory Medicine 40, 496-498.

Saito I, Asano T, Sano K, Takakura K, Abe H, Yoshimoto T, Kikuchi H, Ohta T \& Ishibashi S (1998) Neuroprotective effect of an antioxidant, ebselen, in patients with delayed neurological deficits after aneurysmal subarachnoid hemorrhage. Neurosurgery 42, 269-277.

Salvemini D \& Cuzzocrea S (2003) Therapeutic potential of superoxide dismutase mimetics as therapeutic agents in critical care medicine. Critical Care Medicine 31, S29-S38.

Schuller-Levis GB \& Park E (2004) Taurine and its chloramine: modulators of immunity. Neurochemical Research $\mathbf{2 9}$, 117-126.

Simon EJ, Eisengart A, Sundheim L \& Milhorat AT (1956) Metabolism of vitamin-E. 2. purification and characterization of urinary metabolites of alpha-tocopherol. Journal of Biological Chemistry 221, 807-817.

Soejima A, Matsuzawa N, Hayashi T, Kimura R, Ootsuka T, Fukuoka K, Yamada A, Nagasawa T \& Era S (2004) Alteration of redox state of human serum albumin before and after hemodialysis. Blood Purification 22, 525-529.

Stocker R, Yamamoto Y, McDonagh AF, Glazer AN \& Ames BN (1987) Bilirubin is an antioxidant of possible physiological importance. Science 235, 1043-1046.

Sugino K, Dohi K, Yamada K \& Kawasaki T (1989) Changes in the levels of endogenous antioxidants in the liver of mice with experimental endotoxemia and the protective effects of the antioxidants. Surgery 105, 200-206.

Suzuki E, Yasuda K, Takeda N, Sakata S, Era S, Kuwata K, Sogami M \& Miura K (1992) Increased oxidized form of human serum albumin in patients with diabetes mellitus. Diabetes Research and Clinical Practice 18, 153-158. 
Terawaki H, Yoshimura K, Hasegawa T, Matsuyama Y, Negawa T, Yamada K, Matsushima M, Nakayama M, Hosoya T \& Era $S$ (2004) Oxidative stress is enhanced in correlation with renal dysfunction: examination with the redox state of albumin. Kidney International 66, 1988-1993.

Tuder RM, Zhen L, Cho CY, Taraseviciene-Stewart L, Kasahara Y, Salvemini D, Voelkel NF \& Flores SC (2003) Oxidative stress and apoptosis interact and cause emphysema due to vascular endothelial growth factor receptor blockade. American Journal of Respiratory Cell and Molecular Biology 29, 88-97.

Valencia E, Marin A \& Hardy G (2002) Impact of oral L-glutamine on glutathione, glutamine, and glutamate blood levels in volunteers. Nutrition 18, 367-370.

Wang W \& Ballatori N (1998) Endogenous glutathione conjugates: Occurrence and biological functions. Pharmacological Reviews 50, 335-355.
Waring WS, Webb DJ \& Maxwell SR (2001) Systemic uric acid administration increases serum antioxidant capacity in healthy volunteers. Journal of Cardiovascular Pharmacology 38, 365-371.

Wessner B, Strasser EM, Spittler A \& Roth E (2003) Effect of single and combined supply of glutamine, glycine, Nacetylcysteine, and $R, S$-alpha-lipoic acid on glutathione content of myelomonocytic cells. Clinical Nutrition 22, 515-522.

Yamaguchi T, Sano K, Takakura K, Saito I, Shinohara Y, Asano T \& Yasuhara H (1998) Ebselen in acute ischemic stroke - A placebo-controlled, double-blind clinical trial. Stroke 29, 12-17.

Yang SL, Koo DJ, Chaudry IH \& Wang P (2001) Glycine attenuates hepatocellular depression during early sepsis and reduces sepsis-induced mortality. Critical Care Medicine 29, $1201-1206$ 